\title{
Does Horizontal Inequality Matter in Vietnam?
}

\author{
Thi Thu Hoai Dang ${ }^{1}$ (D)
}

Accepted: 31 March 2018 / Published online: 7 April 2018

(C) UNU-WIDER 2018, corrected publication February 2019

\begin{abstract}
This paper examines the issue of horizontal inequalities in Vietnam over the past 20 years. Using data from three recent Vietnam population censuses (1989, 1999, and 2009) and three Vietnam Household Living Standard Surveys (1998, 2008, 2012), we estimated numerous measures on inequalities between five groups against four welfare indicators. Our results show that horizontal inequality matters in Vietnam, in particular for ethnicity, region, and rural/urban groups. While there has been an improvement in horizontal inequality in education, this paper shows little change in other welfare indicators, in particular poverty. We also found that horizontal inequality does matter for poverty reduction in Vietnam and it needs more attention when designing poverty policies in the future.
\end{abstract}

Keywords Vietnam $\cdot$ Horizontal inequality $\cdot$ Ethnics $\cdot$ Regions $\cdot$ Poverty $\cdot$ Education

JEL Classification $\quad \mathrm{C} 25 \cdot \mathrm{D} 63 \cdot \mathrm{I} 24 \cdot \mathrm{I} 32 \cdot \mathrm{O} 18$

\section{Introduction}

In parallel with a rapid economic growth, Vietnam has been considered as a successful country in poverty reduction over the last decades of development. The poverty rate has been successfully reduced from about $58 \%$ in 1993 to about $15 \%$ in 2014. However, this pattern does not apply equally to all groups in society (Do 2015; Vu and Dang 2015). Some groups have been falling far behind in poverty reduction, such as ethnic-minority groups, groups of households in rural areas, or some regions and provinces of Vietnam. For example, Vu and Dang

The original version of this article was revised due to a retrospective Open Access order.

Thi Thu Hoai Dang

dangthuhoai2004@gmail.com

1 Central Institute for Economic Management (CIEM), 68 Phan Dinh Phung Street, Hanoi, Vietnam 
(2015) find that the headcount poverty rate of the ethnic majority group in Vietnam fell from $26 \%$ in 2002 to $9.9 \%$ in 2012, while that of ethnic-minority groups has only fallen from 74 to $59 \%$. This trend is more or less the same based on various welfare indicators. On the one hand, this contributes to the trend of increasing inequality in Vietnam. The Gini coefficient increased from 0.35 in 1994 to 0.42 in 2012. On the other hand, this creates social division in the society and threatens social stability (UNICEF and FHI 360 2015). This context has stimulated a number of studies on inequality and social division in Vietnam, such as Glewwe et al. (2002), Lee (2008), Rodger and Menon (2010), and Nguyen (2012).

The studies show that group inequality exists in Vietnam in various forms and persists across several indicators. Nguyen and Luu (2015), Doan et al. (2015), Luong (2015), Lee (2008), Rodger and Menon (2010), Nguyen (2012), and Glewwe et al. (2002) show a significant gap in income/wages, education, and healthcare between several groups, such as between rural and urban groups, regions, and genders in Vietnam. In particular, some studies (Dang 2012; Singhal 2015; Van de Walle and Gunewardena 2001) found a welfare gap between ethnic groups. However, no study identifies which type of group-based inequality is more serious in Vietnam and how does it matter for a poverty reduction. Answers to these questions will be useful in designing the poverty reduction policies. Almost all of these studies use simple proportional methods to examine group inequality. None of them provide the aggregate measure of horizontal inequality (HI), except the study by $\mathrm{Vu}$ et al. (2012). However, the $\mathrm{Vu}$ et al. study investigates the horizontal inequality in utilization of public health care services of only one type of group (households in slum vs. non-slum areas). The study also does not use the national representative data, but only the limited data from its own survey. As a result, the current literature on Vietnam limits the comparisons on the group-based inequality across the groups, variables and across nations.

This paper, therefore, will fill this gap and add to the literature in two aspects: First, the paper is a first attempt to calculate the commonly used aggregate HI measures for Vietnamgroup-weighted coefficient of variation (GCOV), group-weighted Gini coefficient (GGini), and group-weighted Theil (GTheil)—along with measures of cross-cuttingness (CC) and cross-fractionalization (CF). It considers four aspects (education, health insurance, durable assets and income) and five types of groups (ethnicity, religion, gender, region and rural/ urban) during the period of 1989-2012. This enables a thorough examination on the issues of $\mathrm{HI}$ in Vietnam over time and enables a comparison in a magnitude of horizontal inequality across groups, aspects and countries. Second, the paper applies the logistic regression model on poverty determinants combined with the results of HI to study the relationship between HI and poverty in Vietnam. In general, it is argued that changes in inequality can have a significant impact on poverty reduction (Naschold 2002; François Bourguignon 2004). Inequality can have a direct effect on poverty, but more importantly an indirect effect through their link with economic growth. HI may create discrimination between different groups in accessing the opportunities to escape poverty. Birdsall et al. (1996) illustrated that highly skewed distribution of human capital is a major constraint to reducing poverty in Latin America and sub-Saharan Africa. This will provide insights on how HI may affect poverty reduction in Vietnam and will be helpful in designing poverty reduction policies.

The rest of the paper is organized as follows. Section 2 briefly discusses the data used for calculations. Section 3 discusses group diversity in Vietnam, and shows the results of fractionalization and polarization indices of ethnic and religious groups in Vietnam. Section 4 shows and discusses the results on various indicators of HI in Vietnam, including education, health insurance, asset ownership, poverty, household consumption. Section 5 examines the relationship between HI and poverty. The paper concludes with Sect. 6, exploring several key factors that may underlie the trends and patterns thus mapped. 


\section{Data}

This paper uses the results of two sets of surveys, the Vietnam Population Census (VPC) and the Vietnam Household Living Standard Survey (VHLSS), which are the two most relevant national representative datasets when examining the issues of HI in Vietnam. The VPC has been conducted every 10 years and the VHLSS every 2 years. Four rounds of the VPC $^{1}$ have been conducted, in 1979, 1989, 1999, and 2009. However, only the results of the most recent three rounds are accessible. Information collected in the census was very basic, covering gender, ethnic group, religion, location (rural/urban; there are eight economic regions in Vietnam), education (by grades and a more detailed six-point educational scale), accommodation (living areas in the VPC 2009), employment, fertility (women), and death. The information on employment in the three most recent rounds was obtained from the representative survey part, whose sample was 5,3 , and $15 \%$ of the population of the census rounds in 1989, 1999, and 2009, respectively.

The data from the VHLSS are used for poverty measurement, welfare, and distribution analysis in Vietnam. These consist of series of national representative surveys, which have been carried out since 1992. The second one was in 1998, and it has been carried out every 2 years since 2002. This type of survey has two modules; the VHLSS-expenditure module (the smaller one) is used for poverty measurement by the Vietnam General Statistics Office (VGSO) and the VHLSS-income module (with a bigger sample) is used for income measurement, although the former also includes the question on income. The data from the VHLSS are very useful for measuring household income and wealth. In addition to the variable on expenditure/consumption (usually used for poverty measurement), the data include other information such as household members' characteristics (age, education, gender), labour and other income, asset ownership, and health.

By combining two sources of survey data, the paper is able to examine the issues for a longer period of time, during 1989-2012 and cover various welfare aspects. This paper examines the $\mathrm{HI}$ on four welfare indicators [education, health insurance and durable assets, income (poverty status and household consumption)]. Education is measured by years of education for the population older than 15 years. ${ }^{2}$ Health insurance is measured by percentage of people in the groups having health insurance. Durable assets are measured by the values of durable assets owned by the households. Poverty is measured by the household headcount poverty rate using national poverty lines. ${ }^{3}$ Consumption is measured by annual household consumption per capita. These four welfare indicators are selected based on their representation on the welfare of people and availability of the data. Of which, poverty, consumption and durable assets are proxies for the well-being of the people while education and health care insurance are considered to be a means to improve the afore mentioned. Although health insurance is only a part of the health care aspect but it's available in the data set. The paper also examines five types of groups (ethnicity, religious, gender, region, urban/rural) based on their significances in the welfare discrimination as identified

\footnotetext{
1 In fact, there were three more population surveys in Vietnam, which were in 1960 and 1973 for North Vietnam and in 1976 for South Vietnam.

2 The calculation for a group of population older than 25 has also been conducted and available upon the request.

3 There are three main poverty lines used in Vietnam. To be comparable with the results of other countries in the project, we used the national poverty line in this paper. This poverty line has changed over time based on the national budget capacity as well as poverty-reduction targets for Vietnam (Gabriel and Vu 2015).
} 
Table 1 Vietnam population by ethnicity and religion (percentages)

\begin{tabular}{lllllllll}
\hline Data source & Groups & & 1989 & 1998 & 1999 & 2008 & 2009 & 2012 \\
\hline VPC & \multirow{2}{*}{ Ethnic } & Kinh & 87.1 & & 86.7 & & 85.8 & \\
& & Others & 12.9 & & 13.3 & & 14.2 & \\
& \multirow{2}{*}{ Religious group } & No & N/A & & 78.9 & & 82.1 & \\
& & Yes & & & 21.1 & & 17.9 & \\
VHLSS & Ethnic & Kinh & & 83.8 & & 86.0 & & 84.1 \\
& & Others & & 16.2 & & 14.0 & & 15.9 \\
& \multirow{3}{*}{ Religious group } & No & & 70.4 & & N/A & & N/A \\
& & Yes & & 29.6 & & & & \\
\hline
\end{tabular}

Source: author's calculations using VPC and VHLSS data

N/A, not available

Table 2 Share of ethnic minorities by region (percentages)

\begin{tabular}{lrrr}
\hline & 1989 & 1999 & 2009 \\
\hline Red river delta & 4.2 & 0.3 & 0.8 \\
North-east & 32.0 & 33.8 & 37.1 \\
North-west & 78.0 & 79.1 & 79.6 \\
North central coastal & 9.4 & 11.6 & 11.9 \\
South central coastal & 5.9 & 5.4 & 6.3 \\
Central highland & 34.4 & 30.9 & 38.1 \\
South-east & 10.1 & 8.7 & 8.0 \\
Mekong river delta & 7.5 & 6.8 & 7.8 \\
\hline
\end{tabular}

Source: author's calculations using VPC data

in the current literature as well as availability of the data. The five groups can be applied only to education aspect due to data constraint.

The VPC recorded the information on ethnicity at the individual level, but the VHLSS data recorded only ethnicity of the household head. Therefore, the calculations/estimations using VHLSS data at the individual level make an assumption that all family members have the same ethnicity as the household head. This does not affect the analysis because the share of ethnic minorities in two sets of data show a similar result in the Table 1 below.

\section{Group Diversity in Vietnam}

Vietnam officially has 54 ethnic groups, of which Kinh is an ethnic majority with more than $80 \%$ of the population, as shown in Table 1 . Among the 53 ethnic minorities, none of them accounts for more than $2 \%$ of the population. Table 1 also shows that most Vietnamese $(82.1 \%$ in 2009$)$ do not officially follow any religion. ${ }^{4}$

The data in Table 2 show that ethnic minorities are highly concentrated in a few regions. In 2009, ethnic minorities accounted for more than $79 \%$ of the population in three

$\overline{4}$ In reality, most Vietnamese unofficially practise some form of Buddhism. 
Table 3 Fractionalization

\begin{tabular}{|c|c|c|c|c|c|c|c|}
\hline Data sources & Groups & 1989 & 1998 & 1999 & 2008 & 2009 & 2012 \\
\hline \multirow[t]{3}{*}{ VPC } & Ethnic (two ethnic groups) & 0.224 & & 0.230 & & $0.244 *$ & \\
\hline & Ethnic (more than two groups) & 0.239 & & 0.246 & & & \\
\hline & Religious group & N/A & & 0.361 & & 0.294 & \\
\hline \multirow[t]{3}{*}{ VHLSS } & Ethnic (two ethnic groups) & & 0.270 & & 0.240 & & 0.267 \\
\hline & Ethnic (more than two groups) & & 0.295 & & 0.258 & & 0.291 \\
\hline & Religious group & & 0.466 & & N/A & & N/A \\
\hline
\end{tabular}

Data from the VPC in 1989 had 54 ethnicities; in 1999, 46 ethnicities and eight religions; in 2009, two ethnicities and two religious. Data from VHLSS in 1988 had 21 ethnicities and eight religions; in 2008,46 ethnicities; in 2012, 51 ethnicities. It is notable that data from the VPC 2009 have 4.9 million observations out of 14.5 million missing data on ethnicities. However, the results of the calculation of the share of ethnic minorities in the population are more or less the same as the official statistics (VGSO 2010)

Source: author's calculations using VPC and VHLSS data

N/A, not available

Table 4 Polarization

\begin{tabular}{llllllll}
\hline Data sources & Groups & 1989 & 1998 & 1999 & 2008 & 2009 & 2012 \\
\hline VPC & Ethnic & 0.397 & & 0.405 & & 0.488 \\
& Religious group & NA & & 0.586 & & 0.587 & 0.459 \\
VHLSS & Ethnic & & 0.464 & & 0.421 & N/A \\
& Religious group & & 0.719 & & N/A & \\
\hline
\end{tabular}

Data from the VPC in 1989 had 54 ethnicities; 1999 had 46 ethnicities and eight religions; in 2009, two ethnicities and two religions. Data from the VHLSS in 1988 had 21 ethnicities and eight religions; in 2008, 46 ethnicities; in 2012, 51 ethnicities

Source: author's calculations using VPC and VHLSS data

N/A, not available

provinces in the north-west region and more than $37 \%$ in the north-east and central highland. Ethnic minorities account for a very low share of the population in the remaining regions.

The results of calculating the fractionalization index for ethnicity and religion in Vietnam over the period 1989-2012 using both datasets are shown in Table 3. The table indicates that Vietnam is a fairly homogeneous society in terms of the population share of ethnicity and religion. The data show a trend of slightly increasing fractionalization over time using VPC data. It is notable that the fractionalization index using VHLSS data tends to be higher than that using VPC data, and the trend is different over time. However, in terms of absolute numbers, the values are not much different, around 0.24-0.29. This level of fractionalization index is much lower than the international average of about 0.44 (Gisselquist and McDoom 2015). It is also noted that the fractionalization values are slightly higher when the ethnicity data are more disaggregated. For example, the value of fractionalization for two ethnic groups (Kinh and ethnic minorities) was 0.23 , while it was 0.246 when the share of 46 ethnic groups was taken into account. 
Table 5 Cross-cuttingness between ethnics and religion, region

\begin{tabular}{llll}
\hline & 1989 & 1999 & 2009 \\
\hline Ethnicity (two groups); religion (two groups) & N/A & 0.94 & 0.97 \\
Ethnicity (more than two groups); religion (two groups) & N/A & 0.83 & N/A \\
Ethnicity (more than two groups); religion (more than two groups) & N/A & 0.67 & N/A \\
Ethnicity (two groups); regions & 0.71 & 0.62 & 0.64 \\
Ethnicity more than two groups); regions & 0.68 & 0.55 & N/A \\
\hline
\end{tabular}

Source: author's calculation using VPC data

N/A, not available

Table 4 shows the results of the polarization index for the two types of groups over the period 1989-2012 using different datasets. It shows a similar pattern as the fractionalization index.

Table 5 shows a high value of cross-cuttingness between ethnicity and religion, and between ethnicity and region. It implies that ethnic groups are quite regionally concentrated and tends to share the same religion.

\section{Horizontal Inequality in Vietnam: Findings and Discussions}

\subsection{Education}

Table 6 presents the results on three HI indicators-GCOV, GGini, and GTheil-of five groups in the population greater than 15 years old during 1989-2012 using two different sources of data. The results show that GCOV of ethnicity in education was in the range $0.11-0.15$ recently. This is a similar range to some other countries in the region [Indonesia was around 0.10 and the Philippines was 0.14-0.15 (Gisselquist and McDoom 2015)]. The value for GGini of ethnic groups increased from 0.028 in 1989 to 0.039 in 2009 and then about 0.05 in 2012. This number is a bit lower than the education GGini average level of other countries, which are around 0.076 (mean education GGini value of 95 countries) (UNICEF and FHI 360 2015). This is partly a result of Vietnamese government's efforts in education. Vietnam had achieved a target of universal primary education in 2010, 5 year earlier than the millennium development goal (MDG) (SRV 2015). The net enrolment rate in primary education reached $98.3 \%$ in $2012-2013$ while the literacy rate of population older than 15 reached $94.7 \%$ in 2012 . The gap in literacy rate among ethnic groups tended to be narrowing overtime.

GCOV for ethnicity increased significantly during 1989-1999, from 0.095 to 0.152 , but experienced a decreasing trend, significantly during 1999-2009. Recently, the reduction of this GCOV indicator of ethnicity was very modest, from 0.154 in 2008 to 0.152 in 2012. The reduction could be a result of various policies on providing assistance to ethnic minorities and remote and less developed areas of Vietnam. Since the late 1980s, the government issued policies on helping ethnic-minority people to study at university. In addition, the government supports building schools through public programmes in ethnic-minority areas (named programme 135), which started to be implemented in 1998. These provided 
Table $6 \mathrm{HI}$ in education for the population older than 15 years (years of education)

\begin{tabular}{|c|c|c|c|c|c|c|c|}
\hline & Data source & Year & Ethnicity & Religion & Region & Gender & Rural/urban \\
\hline \multirow[t]{6}{*}{ GCOV } & \multirow[t]{3}{*}{ VPC } & 1989 & 0.095 & & 0.123 & 0.072 & 0.124 \\
\hline & & 1999 & 0.152 & 0.083 & 0.140 & 0.075 & 0.118 \\
\hline & & 2009 & 0.117 & 0.069 & 0.138 & 0.057 & 0.142 \\
\hline & \multirow[t]{3}{*}{ VHLSS } & 1998 & 0.181 & 0.090 & 0.130 & 0.079 & 0.101 \\
\hline & & 2008 & 0.154 & & 0.145 & 0.065 & 0.120 \\
\hline & & 2012 & 0.152 & & 0.157 & 0.053 & 0.126 \\
\hline \multirow[t]{6}{*}{ GGini } & \multirow[t]{3}{*}{ VPC } & 1989 & 0.028 & & 0.068 & 0.036 & 0.051 \\
\hline & & 1999 & 0.041 & 0.030 & 0.077 & 0.037 & 0.052 \\
\hline & & 2009 & 0.039 & 0.027 & 0.063 & 0.029 & 0.066 \\
\hline & \multirow[t]{3}{*}{ VHLSS } & 1998 & 0.055 & 0.036 & 0.070 & 0.040 & 0.043 \\
\hline & & 2008 & 0.046 & & 0.080 & 0.032 & 0.054 \\
\hline & & 2012 & 0.050 & & 0.088 & 0.027 & 0.058 \\
\hline \multirow[t]{6}{*}{ GTheil } & \multirow[t]{3}{*}{ VPC } & 1989 & 0.005 & & 0.008 & 0.003 & 0.007 \\
\hline & & 1999 & 0.015 & 0.004 & 0.010 & 0.003 & 0.007 \\
\hline & & 2009 & 0.007 & 0.002 & 0.010 & 0.002 & 0.010 \\
\hline & \multirow[t]{3}{*}{ VHLSS } & 1998 & & 0.043 & 0.009 & 0.003 & 0.005 \\
\hline & & 2008 & 0.015 & & 0.011 & 0.002 & 0.007 \\
\hline & & 2012 & 0.014 & & 0.012 & 0.001 & 0.008 \\
\hline
\end{tabular}

Source: author's calculations using VPC and VHLSS data

various types of assistance to ethnic minorities and less developed areas, including assistance in education. ${ }^{5}$

Beside the educational divide among ethnic groups, the results show that regional and rural/urban divides in education are also notable in Vietnam. The GCOVs of regions and rural/urban in education was 0.15 and 0.12 in 2012, respectively. More importantly, these indicators tend to slightly increase over time for regions, from about 0.12 in 1989 to about 0.15 in 2012, and tend to be maintained over time for rural/urban, at about 0.12 during 1989-2012. These urban/rural and regional divides in education do not necessarily reflect the ethnic divide as mentioned above. This is due to the fact that the GCOV of region and urban/rural in education in 2012 was still at the same level, about 0.16 and 0.11 , when three high-density ethnic-minority regions (north-east, north-west, and central highland, as shown in Table 2) were taken out of the sample.

Table 6 also shows that education inequality matters less for religion and gender groups than ethnicity, region, and rural/urban groups, as mentioned above. The GCOV in education by gender has been reduced from 0.072 to about 0.053 during 1989-2012. The GCOV of religion group shared a similar trend. Table 6 demonstrates a similar trend in three HI indicators-GCOV, GGini, and GTheil-for all five groups over time.

The results show that there are differences in the values of HI indicators for education when using different data sources, but the trend and relative magnitude of $\mathrm{HI}$ indicators

\footnotetext{
5 The programme of economic and social development of special difficulty communes in mountainous and ethnic minority areas issued in 1998 by Decision No. 135 (QĐ 135/1998/QĐ-TTg), usually called by the popular short name 'programme 135' in Vietnam.
} 
Table $7 \mathrm{HI}$ in health insurance

\begin{tabular}{rlll}
\hline & Ethnics & Regions & Urban/rural \\
\hline GCOV & & & \\
1998 & 0.429 & 0.366 & 0.447 \\
2008 & 0.332 & 0.285 & 0.036 \\
2012 & 0.253 & 0.202 & 0.056 \\
GGini & & & \\
1998 & 0.120 & 0.205 & 0.193 \\
2008 & 0.110 & 0.151 & 0.016 \\
2012 & 0.087 & 0.106 & 0.025 \\
GTheil & & & \\
1998 & & 0.072 & 0.088 \\
2008 & 0.045 & 0.039 & 0.001 \\
2012 & 0.027 & 0.019 & 0.002 \\
\hline
\end{tabular}

Source: author's calculations using VHLSS data

among different groups are similar. For example, the GCOV value for ethnicity in Vietnam was around 0.12-0.15 during 1999-2009 when using the VPC, while it was a bit higher, about 0.15-0.18, when using the VHLSS during 1998-2008. The survey sample of the VPC is larger than that of the VHLSS and it is designed to survey the Vietnamese population, while the VHLSS is designed to examine the living standards (income and expenditure) of households. In this sense, VPC data tend to be more reliable. ${ }^{6}$ However, the data from the VPC are less up-to-date compared to the VHLSS due to less frequent surveys.

\subsection{Health Insurance}

Table 7 indicates the GCOV on health insurance by ethnic and other groups. Health insurance is measured by mean percentage of people in the groups having health insurance. The results show that the value of GCOV for ethnic groups was reduced from 0.429 in 1998 to 0.332 in 2008 , then was reduced further to 0.253 in 2012 . These GCOV values on health insurance, on average, were higher than those for education shown in Table 6. However, the interpretation of GCOV on health insurance is very different to the GCOV on education when the simple proportion indicators of health insurance are examined. The survey data show that the share of the ethnic majority (Kinh people) having health insurance was $40.4 \%$, while the share of ethnic minorities was $71.6 \%$ in 2008 ; the share was 49.3 and $80.5 \%$ in 2012 , respectively. In other words, unlike GCOV on education, the high value of ethnic GCOV for health insurance did not reflect the disadvantage of ethnic minorities in health insurance access compared to the ethnic majority, but actually the opposite. This is probably the result of government policies to support health insurance for the poor, who are mainly ethnic minorities. However, given a big income gap between ethnic minorities and the majority, the government support of health insurance for the poor seem not to be enough to have a significant impact on their poverty status. This also shows that GCOV

\footnotetext{
${ }^{6}$ Although the errors of data of the larger sample can be influenced more by measurement errors compared to the smaller sample.
} 
Table $8 \mathrm{HI}$ in poverty and household consumption

\begin{tabular}{|c|c|c|c|c|c|c|}
\hline & \multicolumn{3}{|l|}{ Poverty } & \multicolumn{3}{|c|}{ Consumption } \\
\hline & Ethnicity & Regions & Urban/rural & Ethnicity & Regions & Urban/rural \\
\hline \multicolumn{7}{|l|}{ GCOV } \\
\hline 1998 & 0.436 & 0.400 & 0.432 & 0.219 & 0.320 & 0.431 \\
\hline 2008 & 1.313 & 0.728 & 0.497 & 0.200 & 0.296 & 0.386 \\
\hline 2012 & 1.759 & 0.886 & 0.455 & 0.211 & 0.236 & 0.337 \\
\hline \multicolumn{7}{|l|}{ GGini } \\
\hline 1998 & 0.152 & 0.213 & 0.180 & 0.077 & 0.158 & 0.180 \\
\hline 2008 & 0.378 & 0.386 & 0.222 & 0.069 & 0.152 & 0.173 \\
\hline 2012 & 0.525 & 0.443 & 0.208 & 0.075 & 0.127 & 0.154 \\
\hline \multicolumn{7}{|l|}{ GTheil } \\
\hline 1998 & 0.078 & 0.087 & 0.128 & 0.025 & 0.046 & 0.081 \\
\hline 2008 & & 0.255 & 0.165 & 0.025 & 0.040 & 0.068 \\
\hline 2012 & & 0.339 & 0.129 & 0.028 & 0.027 & 0.053 \\
\hline
\end{tabular}

Source: author's calculations using VHLSS data

indicators should be examined together with simple proportion indicators in order to obtain the correct picture on $\mathrm{HI}$.

Table 7 also indicates almost no recent significant difference in health insurance between rural/urban groups. This is a result of government policies on providing free health insurance for the poor in general, the majority of which live in rural areas and for the ethnic minority in particular. The most direct policy is a program 139 established in $2002,{ }^{7}$ issuing free health care certificates for 4.15 million poor people after 2 years of implementation (Nguyen and Bob 2007).

\subsection{Poverty and Household Consumption}

Table 8 shows the GCOV on the poverty rate and household consumption for three types of group. Poverty is measured by the mean headcount poverty rate of groups; consumption is measured by mean annual household consumption per capita. This indicator is calculated at the household level using the VHLSS.

In terms of poverty, the results show a significant high GCOV for ethnicity during 2008-2012, at 1.313 and 1.759. These values reflect a big gap in the poverty rate between ethnic groups in Vietnam. In fact, the headcount poverty rate of ethnic minorities in Vietnam was $30.07 \%$, while the rate of the ethnic majority was as low as $3.21 \%$ in 2012, and was 36.84 and 6.18 in 2008, respectively. It is notable that the value of the GCOV on poverty of ethnic minorities increased over time, although the poverty rates of all groups fell. This seems to be in line with the widening gap between the living standards of the ethnic majority and minorities, as shown in the literature (Singhal and Beck 2015). This also shows that all the government's efforts to help the poor in general and ethnic minorities in particular could not narrow this gap during

\footnotetext{
${ }^{7}$ Decision numbered 139/2002/QD-TTg of Prime Minister.
} 
Table 9 HI in assets ownership

\begin{tabular}{rlll}
\hline & Ethnicity & Regions & Urban/rural \\
\hline GCOV & & & \\
1998 & 0.386 & 0.586 & 0.676 \\
2008 & 0.241 & 0.350 & 0.448 \\
2012 & 0.258 & 0.270 & 0.367 \\
GGini & & & \\
1998 & 0.132 & 0.283 & 0.293 \\
2008 & 0.084 & 0.187 & 0.203 \\
2012 & 0.094 & 0.140 & 0.168 \\
GTheil & & & \\
1998 & 0.075 & 0.146 & 0.194 \\
2008 & 0.038 & 0.058 & 0.091 \\
2012 & 0.044 & 0.036 & 0.062 \\
\hline
\end{tabular}

Source: author's calculations using VHLSS data

1998-2012. ${ }^{8}$ In particular, unlike the decreasing trend of $\mathrm{HI}$ in education and ethnicity during 1998-2012 shown in Table 6, HI in poverty kept rising during this period. This illustrates that in addition to the assistance for ethnic minorities in education, to narrow the welfare gap between ethnic groups the Vietnamese government needs to expend greater effort in improving the economic development of the areas in which ethnic minorities are located.

The poverty gap among regions was about 0.886 in 2012, and was lower between rural and urban groups, at about 0.455 . It is notable that the GCOV in poverty for regions tended to increase over time during 1998-2012, while the trend of urban and rural groups was not clear; it slightly increased during 1988-2008, then slightly decreased recently.

Table 8 shows that the HI in household consumption during 1998-2012 was not as strikingly high as that in poverty. This demonstrates that the gap in living standards among ethnic groups was more severe between the lowest extreme and the one above the poverty line. In particular, the gap among ethnic groups was reduced during 1998-2008, but started rising again recently.

\subsection{Assets Ownership}

Table 9 shows the results of three HI indicators by three types of groups on asset ownership, measured by the mean values of durable assets owned by the households in different groups. The values of GCOV on asset ownership were 0.258 for ethnic groups to the disadvantage of ethnic-minority households and 0.367 on rural/urban groups to the disadvantage of rural households. In terms of welfare aspect, durable assets represent the consumption over the longer period of time, or is proxy for the wealth. In this regards, the trend of inequality among groups on wealth shares the same pattern as that of consumption in Table 8 .

\footnotetext{
${ }^{8}$ Beside programme 135 mentioned above, Vietnam also had a national programme on poverty in general and a programme on rapid and sustainable poverty reduction for 61 poor districts, which started to be implemented in 2008 [issued by Resolution number 30A by the government (NQ 30a/2008/NQ-CP)], named programme $30 \mathrm{a}$.
} 


\section{Horizontal Inequality and Poverty}

In this section we examine the correlation between $\mathrm{HI}$ and poverty. We use multi-level logistic regression models on poverty determinants using the VHLSS data at the individual level for those aged older than 15 years. The dependent variable is the poverty status of the individual in 2012; 0 is non-poor and 1 is poor. Since poverty status is defined at the household level (as mentioned in Sect. 2), individuals in the same household have the same poverty status. Independent variables are the main poverty determinants in Vietnam, as identified in the poverty literature (Dang 2011; World Bank Institute 2015). These include seven variables: years of education; total value of assets; ethnicity; gender; age; rural/urban; and region. Of which, the variables, years of education and total value of assets are identified as in the previous sections of this paper. Ethnicity, gender and rural/urban are dummy variables whose references are ethnic minority, male and rural areas, respectively. In addition, in order to examine the relation between $\mathrm{HI}$ and poverty, four variables on $\mathrm{HI}$ are included in four logistic regression models, as shown in Table 10. These are GCOV indicators in education and assets of two types of groups at the provincial level: ethnicity and urban/ rural group. ${ }^{9}$

The hypothesis here is that individuals located in the provinces that have a bigger gap in education or asset ownership between either ethnicity or rural/urban areas will have a higher probability of being poor. Four models have the same independent variables except the variable on horizontal inequality (GCOV). Of which, the first model includes the GCOV variable on education by ethnicity, the second one includes the GCOV variable on education by urban/rural, the third one includes the GCOV variable on asset by ethnicity, the fourth one includes the GCOV variable on asset by rural/urban.

The results of four models are presented in turn in four columns of the Table 10. It shows that all $\mathrm{HI}$ variables have positive coefficients at a statistical level less than $1 \%$. It implies that a higher degree of $\mathrm{HI}$ in education and asset ownership between ethnicity and urban/rural areas the higher probability of individuals falling into poverty. This shows that the improvement in the education gap among ethnic group recently as found in the previous section was not enough for the poverty reduction for the ethnic minority. Similarly, the inequality in rural/urban areas in education as well as inequality in assets can be a factor that increase the probability of being poor. In short, this shows that HI does matter for poverty reduction in Vietnam and should be taken into account in the future poverty reduction policies.

\section{Conclusions}

This paper uses two sets of the most relevant survey data for Vietnam to examine the issues of group-based inequality. This paper is the first attempt in the literature to calculate a group of horizontal inequality indicators (GCOV, GGini, GTheil) on four different welfare aspects for Vietnam during more than 20 year period. The results show that Vietnam's society is quite homogeneous in terms of population share by both ethnic and religious

\footnotetext{
9 Vietnam had 63 provinces in 2012 therefore there are 63 values of each HI indicator for 63 provinces. It is easy to run the similar models for two other HI indicators, GGini and GTheil however, as shown in previous sections, the results on GGnini and GTheil to a large extent are similar to that of GCOV therefore this applies to GCOV only.
} 


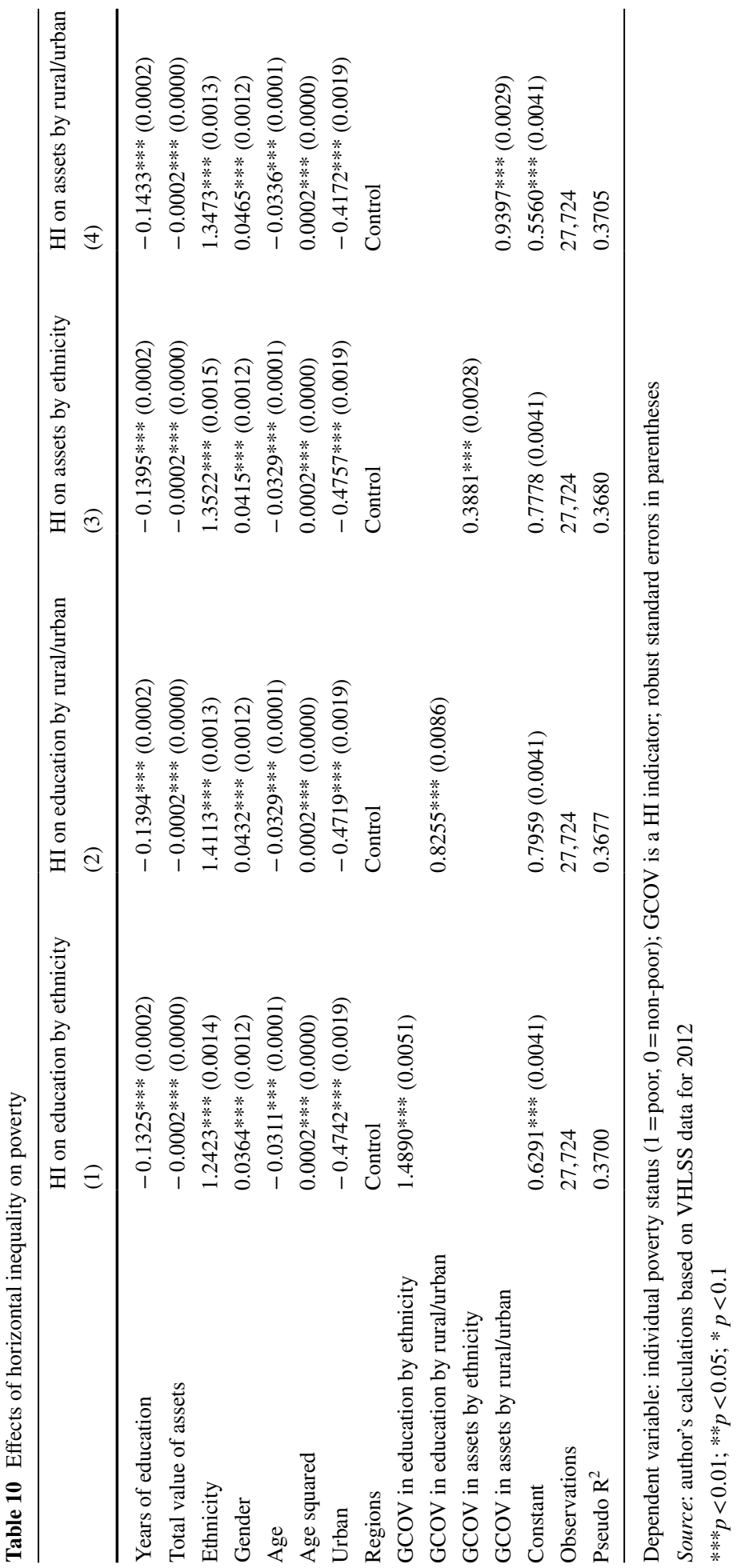


groups, whereas the picture is very different when the HI in welfare indicators is taken into consideration. The society becomes highly divided in terms of the poverty headcount rate between ethnic groups. More importantly, the trend becomes worse over time and there has been no sign of recent improvement. Although the paper shows that the gap in education among ethnic groups has been improved, it may still be a factor that increases the probability to be poor. This may imply a quest for a better effort of the Government in closing further the education gap among ethnic groups and also that the improve in many other factors, as pointed out in other studies such as land holding and access to credit, returns on assets (Glewwe et al. 2002), and income diversification (Singhal and Beck 2015).

Besides poverty, the paper shows a less divided society in terms of education, health insurance, and asset ownership. Although the gap in possession of health insurance exists, the share of ethnic minorities having health insurance was much higher than that of the ethnic majority. This is a result of government support of health insurance for the poor. However, it is not enough to close the poverty gap between ethnic minorities and the majority unless more policy efforts can be made. This paper also indicates that HI indicators should be used together with simple proportion indicators in order to get the correct picture of the nature of group-based inequality. The results show GCOV, GGini, and GTheil are consistent in showing the trend and patterns of group-based inequality.

Finally, despite a recognized rapid reduction in poverty, Vietnam still faces challenges in managing poverty reduction for ethnic minorities and to some extent for rural/urban. In this sense, the issue of $\mathrm{HI}$ in education and asset ownership matters for poverty reduction and it should be given a due attention when designing poverty policies in the future.

Open Access This book is licensed under the terms of the Creative Commons Attribution-NonCommercialShareAlike 3.0 IGO License (https://creativecommons.org/licenses/by-nc-sa/3.0/igo/), which permits any noncommercial use, sharing, adaptation, distribution, and reproduction in any medium or format, as long as you give appropriate credit to the UNU-WIDER, provide a link to the Creative Commons licence and indicate if changes were made. If you remix, transform, or build upon this book or a part thereof, you must distribute your contributions under the same licence as the original.

\section{References}

Birdsall, N., Pinckney, T., \& Sabot, R. (1996). Why low inequality spurs growth: Savings and investment by the poor. Washington, DC: Inter-American Development Bank.

Bourguignon, F. (2004). The poverty-growth-inequality triangle. The paper was presented at the Indian Council for Research on International Economic Relations, New Delhi, February 4, 2004.

Dang, H. A. (2012). A widening poverty gap for ethnic minorities. In G. H. Hall \& H. A. Patrinos (Eds.), Indigenous peoples, poverty and development. Cambridge: Cambridge University Press.

Dang, T. T. H. (2011). Poverty reduction in Vietnam: The effects of shocks and growth patterns. Ph.D. thesis, University of Glasgow.

Do, T. K. (2015). Trends in inequalities in living standards in Vietnam for 20 years of innovation (1992/932012). In Proceedings of the scientific conference on socioeconomic forecast serves medium-term planning in the context of international integration. Hanoi: Hong Duc Publishing House.

Doan, H. Y., Nguyen, T. T. T., \& Nguyen, H. L. (2015). Analysis of income inequality by regions in Vietnam through the approach of income decompositions. In Proceedings of the scientific conference on socioeconomic forecast serves medium-term planning in the context of international integration. Hanoi: Hong Duc Publishing House.

Gabriel, D., \& Vu, L. H. (2015). Demystifying poverty measurement in Vietnam. World Bank Vietnam development economics discussion paper 1. Washington, DC: World Bank.

Gisselquist, R., \& McDoom, O. S. (2015). The conceptualization and measurement of ethnic and religious divisions. UNU-WIDER working paper 2015/022. Helsinki: UNU-WIDER. 
Glewwe, P., Gragnolati, M., \& Zaman, H. (2002). Who gained from Vietnam's boom in the 1990s? Economic Development and Cultural Change, 50(4), 773-792.

Lee, S. (2008). How do women fare in education, employment and health?. Hanoi: World Bank Vietnam.

Luong, T. N. O. (2015). The impact of gender inequality to grow in Vietnam. Ph.D. thesis, CIEM.

Naschold, F. (2002). Why inequality matters for poverty. Briefing Paper 2. London: Overseas Development Institute.

Nguyen, T. T. P., \& Bob, B. (2007). A review of ethnic minority policies and programs in Vietnam. Working paper.

Nguyen, T. H., \& Luu, B. N. (2015). Approach innovation and growing strategic to address income inequality in Vietnam. In Proceedings of the scientific conference on socioeconomic forecast serves mediumterm planning in the context of international integration. Hanoi: Hong Duc Publishing House.

Nguyen, V. C. (2012). Gender equality in education, health care and employment: Evidence from Vietnam. Working paper. Germany: University Library of Munich.

Rodger, Y., \& Menon, N. (2010). Gender differences in socioeconomic status and health: Evidence from Vietnam household living standard survey in 2008. Hanoi: World Bank Vietnam.

Singhal, S., \& Beck, U. (2015). Ethnic disadvantage in Vietnam: Evidence using panel data. UNU-WIDER Working paper 2015/097. Helsinki: UNU-WIDER.

SRV (Socialist Republic of Vietnam) (2015). 15 Years achieving the Vietnam millennium development goals. A country report.

UNICEF and FHI 360. (2015). Does horizontal education inequality lead to violent conflict?. New York: UNICEF.

Van de Walle, D., \& Gunewardena, D. (2001). Sources of ethnic inequality in Viet Nam. Journal of Development Economics, 65(1), 177-207.

VGSO (Viet Nam General Statistics Office). (2010). The 2009 Vietnam population and housing census: Completed results. Hanoi: Statistical Publishing House.

Vu, X. N. H., \& Dang, T. T. H. (2015). Scoping Study on integration of poverty and sustainability into national development planning: Vietnam country report. Hanoi: UNDP.

Vu, D. K., Van Hoang, M., Kim, B. G., Lars, W., \& Nawi, N. (2012). Horizontal inequity in public health care service utilization for non-communicable diseases in urban Vietnam. Global Health Action. https ://doi.org/10.3402/gha.v7.24919.

World Bank Institute. (2015). Understanding the determinants of poverty. In Introduction to poverty analysis (Chap. 8, pp. 124-136). 